\title{
Article \\ Effect of Quarry Rock Dust as a Binder on the Properties of Fly Ash and Slag-Based Geopolymer Concrete Exposed to Ambient and Elevated Temperatures
}

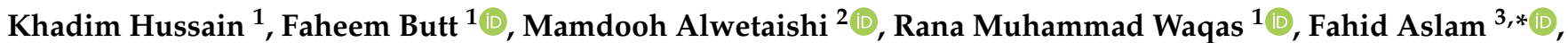 \\ Muhammad Ibraheem ${ }^{1}$, Zhu Xulong ${ }^{4, *}$, Naveed Ahmad ${ }^{1}$, Rana Faisal Tufail ${ }^{5, *}$, Muhammad Ali Musarat ${ }^{6, *}$ (D) \\ and Enas E. Hussein ${ }^{7}$ (D)
}

Citation: Hussain, K.; Butt, F.; Alwetaishi, M.; Waqas, R.M.; Aslam, F.; Ibraheem, M.; Xulong, Z.; Ahmad N.; Tufail, R.F.; Musarat, M.A.; et al. Effect of Quarry Rock Dust as a Binder on the Properties of Fly Ash and Slag-Based Geopolymer Concrete Exposed to Ambient and Elevated Temperatures. Appl. Sci. 2021, 11 , 9192. https://doi.org/10.3390/ app11199192

Academic Editor: Stefano Invernizzi

Received: 23 August 2021

Accepted: 28 September 2021

Published: 2 October 2021

Publisher's Note: MDPI stays neutral with regard to jurisdictional claims in published maps and institutional affiliations.

Copyright: (c) 2021 by the authors Licensee MDPI, Basel, Switzerland. This article is an open access article distributed under the terms and conditions of the Creative Commons Attribution (CC BY) license (https:// creativecommons.org/licenses/by/ $4.0 /)$
1 Department of Civil Engineering, University of Engineering and Technology, Taxila 47050, Pakistan; hussainkhadim173@gmail.com (K.H.); faheem.butt@uettaxila.edu.pk (F.B.); rana.waqas@uettaxila.edu.pk (R.M.W.); Ibrahim.123456@yahoo.com (M.I.); naveed.ahmad@uettaxila.edu.pk (N.A.)

2 Department of Civil Engineering, College of Engineering, Taif University, Taif 21974, Saudi Arabia; m.alwetaishi@tu.edu.sa

3 Department of Civil Engineering, College of Engineering in Al-Kharj, Prince Sattam Bin Abdulaziz University, Al-Kharj 11942, Saudi Arabia

4 Department of Civil Engineering, College of Architecture and Environment, Sichuan University, Chengdu 610017, China

5 Department of Civil Engineering, Wah Campus, COMSATS University Islamabad, Wah Cantt 47040, Pakistan

6 Department of Civil and Environmental Engineering, Universiti Teknologi PETRONAS, Bandar Seri Iskandar 32610, Malaysia

7 National Water Research Center, P.O. Box 74, Shubra El-Kheima 13411, Egypt; enas_el-sayed@nwrc.gov.eg

* Correspondence: f.aslam@psau.edu.sa (F.A.); zhuxulong2021@163.com (Z.X.); faisal.tufail@ciitwah.edu.pk (R.F.T.); muhammad_19000316@utp.edu.my (M.A.M.)

\begin{abstract}
This study presents the performance of quarry rock dust (QRD) incorporated fly ash (FA) and slag (SG) based geopolymer concretes (QFS-GPC) exposed to ambient and elevated temperatures. A total of five QFS-GPC mix types were prepared. The quantity of FA (50\%) was kept constant in all the mixes, and SG was replaced by $5 \%, 10 \%, 15 \%$, and $20 \%$ of QRD. The fresh, hardened properties of the QFS-GPC mixes, viz., workability, compressive strength, splitting tensile strength, and flexural strengths, and XRD for identification of reaction phases were evaluated. The prepared mixes were also heated up to $800{ }^{\circ} \mathrm{C}$ to evaluate the residual compressive strength and weight loss. The workability of the QFS-GPC mixes was observed to be reduced by increasing the dosage (0 to $20 \%$ ) of QRD. Superplasticizer (SP) was used to maintain the medium standard of workability. The compressive, tensile, and flexural strengths were increased by replacing SG with QRD up to 15\%, whereas a further higher dosage (20\%) of QRD reduced the mechanical strengths of the QFS-GPC mixes. The strength of the QFS-GPC specimens, heated to elevated temperatures up to $800{ }^{\circ} \mathrm{C}$, was reduced persistently with the increased contents of QRD from 0 to $20 \%$. It was concluded from the study that QFS-GPC can be used to achieve $30 \mathrm{MPa}$ strength of concrete.
\end{abstract}

Keywords: geopolymer; elevated temperature; compressive; quarry rock dust

\section{Introduction}

The ordinary Portland cement (OPC) has been used as a major ingredient for construction activities worldwide, which is generally used as a binder in the concrete [1,2]. The ecological benefits and engineering properties of concrete have been improved by geopolymers, an alternative for the OPC/conventional concrete [3,4]. The geopolymer concrete (GPC) possesses good engineering properties with reduced emission of greenhouse gases and is also known as green concrete [5]. GPC can not only lessen the carbon footprint associated with OPC but can also use a bulk quantity of industrial by-product/waste materials 
such as fly ash (FA), blast furnace slag (SG), ceramic wastes, and silica fumes, etc. [5-8]. The waste materials such as FA, rice husk ash, SG, metakaolin, mine waste, silt, tungsten, iron, copper and gold ores, marble, and some industrial by-products are a promising hazard to the environment. Fossil fuels are used in thermal power plants to generate electricity that produces a significant quantity of FA wastes, about 800 million tonnes globally [9], out of which only a minor portion (20-30\%) is used [10]. The improper dumping of this residue causes environmental issues such as water and air pollution. Some of these materials can be used as building materials, thus reducing landfill costs and protecting the environment from harmful effects. Therefore, GPC has been under study due to its relatively better mechanical properties and environmental benefits. The polymeric materials are inorganic and produce geopolymers by the polymerization of aluminosilicates with alkaline solutions that harden and strengthen at ambient temperatures [11].

The GPC has two main constituents other than the aggregates: aluminosilicate source materials and an alkaline activator solution (AAS). The most used alkaline activator is a combination of sodium silicate (SS) and sodium hydroxide (SH) solutions, though potassium hydroxide and potassium silicate can also be used. AAS plays an important role in the polymerization process [12]. The source binder materials in a GPC must have silicate and aluminate in a significant amount. The use of local raw materials is an important consideration and is suitable for an economical and geofriendly environment. The benefits of using local raw materials include low transportation cost, low amount of energy for transportation, better overall control, and reduced emissions and energy usage. The local natural sources of aluminosilicate materials are bentonite and metakaolin clay, mine waste, silt, tungsten, iron, copper and gold ores, etc. $[6-8,13]$, whereas the waste by-product materials FA [14,15], SG [16], ceramic wastes, and silica fumes [17], etc., can be used for the preparation of geopolymer concrete due to their abundant availability.

The selection of source materials for making GPC depends on numerous factors including availability, cost, and applications [18]. Most researchers have worked on the development of GPC with heat curing $[19,20]$. The FA has been used as an appropriate raw material for GPC due to its wide range of availability and suitable composition of alumina and silica. The previous studies [19,21] have described that FA-based GPC has good durability and mechanical properties after heat curing at 60 to $85^{\circ} \mathrm{C}$. At ambient temperature, the reaction process of FA is too slow [15]. The heat curing conditions are generally appropriate for industrial precast constructed members and usually cannot be practiced for cast-in-situ construction. Hence, it is important to develop a type of GPC without heat curing to expand its field and site application. This can further reduce the cost and energy consumption linked with the elevated temperature curing.

A few studies have tried to improve the reactivity of FA by varying the SS/SH ratios, alkaline activating content, and molarity of SH to achieve good results at the ambient curing conditions [22]. One of the acceptable methods is to add calcium-rich materials such as SG in GPC at ambient curing conditions. The inclusion of calcium-rich materials in GPC can accelerate FA dissolution and improve reaction product formation at ambient curing conditions [23]. The incorporation of SG in GPC results in better engineering properties at ambient conditions $[3,4,24,25]$. Several studies have been carried out to investigate the effect of SG on the fresh, mechanical, and durability properties of GPC [3,4,16,23-25].

The QRD is a calcium-rich waste material of the rock crushing industry that is produced as a cloud of unwanted dust during the manufacturing process of coarse aggregates. A portion of this unwanted waste is often used on-site as a filling material for the quarry pits. This waste can be effectively used as a construction material to preserve the environment and natural resources. The QRD has been used as a partial replacement of sand in GPC [24] and mortars [25]. The consumption of QRD in concrete is recommended mainly in the regions where the sand is not available in abundant quantity [26]. The suitability of QRD to be used as a sand replacement material shows superior mechanical properties of concrete such as compressive, tensile, and flexural strengths [26-28]. The complete replacement of sand with QRD gave superior compressive strength properties [29]. 
The QRD having a surface area of $6000 \mathrm{~cm}^{2} / \mathrm{g}$ can be utilized as a precursor to making alkali-activated binders [30]. It was identified that a combination of an equal amount of QRD waste and OPC contents usually reduced the superplasticizer (SP) requirements and enhanced the compressive strength of OPC concrete cubes [27]. Some studies have used QRD as a partial replacement of sand in GPC concrete [28,31-35]; however, studies on the development of a GPC mix by blending quarry rock dust (QRD) wastes as a binding agent are rather limited [36,37].

This study has been undertaken to investigate the effects of QRD wastes as a binding agent on the engineering properties of GPC mixes containing low calcium FA and SG. The QRD waste is used as a partial replacement of SG (a binder material) in the QRD, FA, and SG-based GPC (QFS-GPC) mix to produce eco-friendly construction material. The SG was replaced by $0 \%, 5 \%, 10 \%, 15 \%$, and $20 \%$ of QRD. The objective of the present study is to observe the performance of QFS-GPC for workability and mechanical properties at ambient temperature curing conditions. According to the building codes, structural concrete members should fulfill the fire safety requirements [36,37] since the buildings may be exposed to fire hazards. Generally, the best fire resistance properties of concrete are achieved by alkali-activated mortars (AAMs) when used in construction as building material [32]. Therefore, in the present study, the fire resistance properties such as the residual compressive strength and the weight loss of the QFS-GPC mix specimens will also be determined at elevated temperatures, i.e., 400 and $800{ }^{\circ} \mathrm{C}$ by heating the specimens in a controlled electric furnace.

In the current study, the main intension of using QRD waste as geopolymer binding material is to meet the annual production of concrete due to limited production of FA, SG, and other waste materials. The use of QRD as a geopolymer binder is very limited as it has only been used as a filler material. The performance of QRD-incorporated fly ash (FA) and slag (SG) based geopolymer concretes exposed to ambient and elevated temperatures is investigated. An optimal mix of QFS-GPC will be ascertained based on the performance criteria mentioned above. Moreover, the contributing influence on the mechanical and thermal resistance properties of geopolymer concrete was focused and discussed herein.

\section{Experimental Program}

The experimental program includes the preparation of source materials for preparing the QFS-GPC mix types, mixing of the ingredients, preparation of samples for different test types, and performance of the tests to determine fresh, mechanical, and elevated temperature properties. The following subsections provide detail of the material specifications, mix types and proportions, and specimens for different tests according to the standard practice.

\subsection{Material Specifications}

The three waste materials used as the source materials in QFS-GPC are QRD, FA, and SG. The QRD wastes were obtained from the quarries at Margallah Hills located near Taxila (Pakistan). The QRD is collected at the bottom of the aggregate crushers during the formation of the coarse aggregates. It was ground to achieve the required size equivalent to the OPC particles, which can be sieved through a $45-\mu \mathrm{m}$ sieve [28]. The grinding process of the QRD is shown in Figure 1. The quarry waste was obtained from the Margalla stone hill crushers and was subjected to ball mill grinding machine for 2 days in laboratory. Furthermore, the resulting $90 \%$ material passing $45 \mu \mathrm{m}$ was used. The FA and SG used in the present study are shown in Figure 2. The processed SG used in this study has pozzolanic and cementitious properties confirming ASTM C989/C989M-18a [34]. The color of SG looks off-white due to the occurrence of hydraulic reaction of water during mixing, and its particle size was $45 \mu \mathrm{m}$. The low-calcium FA (Class F), taken from Port Qasim coal-fired power plant in Karachi (Pakistan), was used as a source of aluminosilicate constituents for preparing of GPC mixes with QRD and SG. The appearance of FA was grey and fulfills the requirement of the ASTM C618-19 [35]. The X-ray fluorescence (XRF) spectroscopy was used to assess the chemical composition of FA, SG, and QRD as summarized in 
Table 1 . The silica and alumina compositions are $58.32 \%$ and $29.5 \%$ in FA, $34.38 \%$ and $12.98 \%$ in SG, and $9.35 \%$ and $1.64 \%$ in QRD, respectively, in the binder materials (Table 1). The QRD has the highest content of calcium oxides $(\mathrm{CaO})$, i.e., $47.13 \%$ as compared to SG $(37.33 \%)$ and FA (1.57\%). The level of calcium, aluminum, and silica oxides played an important role in the geopolymer matrix by forming calcium silicate hydrate (CSH), calcium aluminum silicate hydrate (CASH), and sodium aluminosilicate hydrate (NASH) in the polymerization procedure [32,33]. For comparing the mechanical properties of QFS-GPC with the conventional/OPC concrete, OPC-conforming ASTM type II [25] has been used for control specimens to compare with the GPC specimens. The physical properties and chemical composition of the OPC used are presented in Table 2.

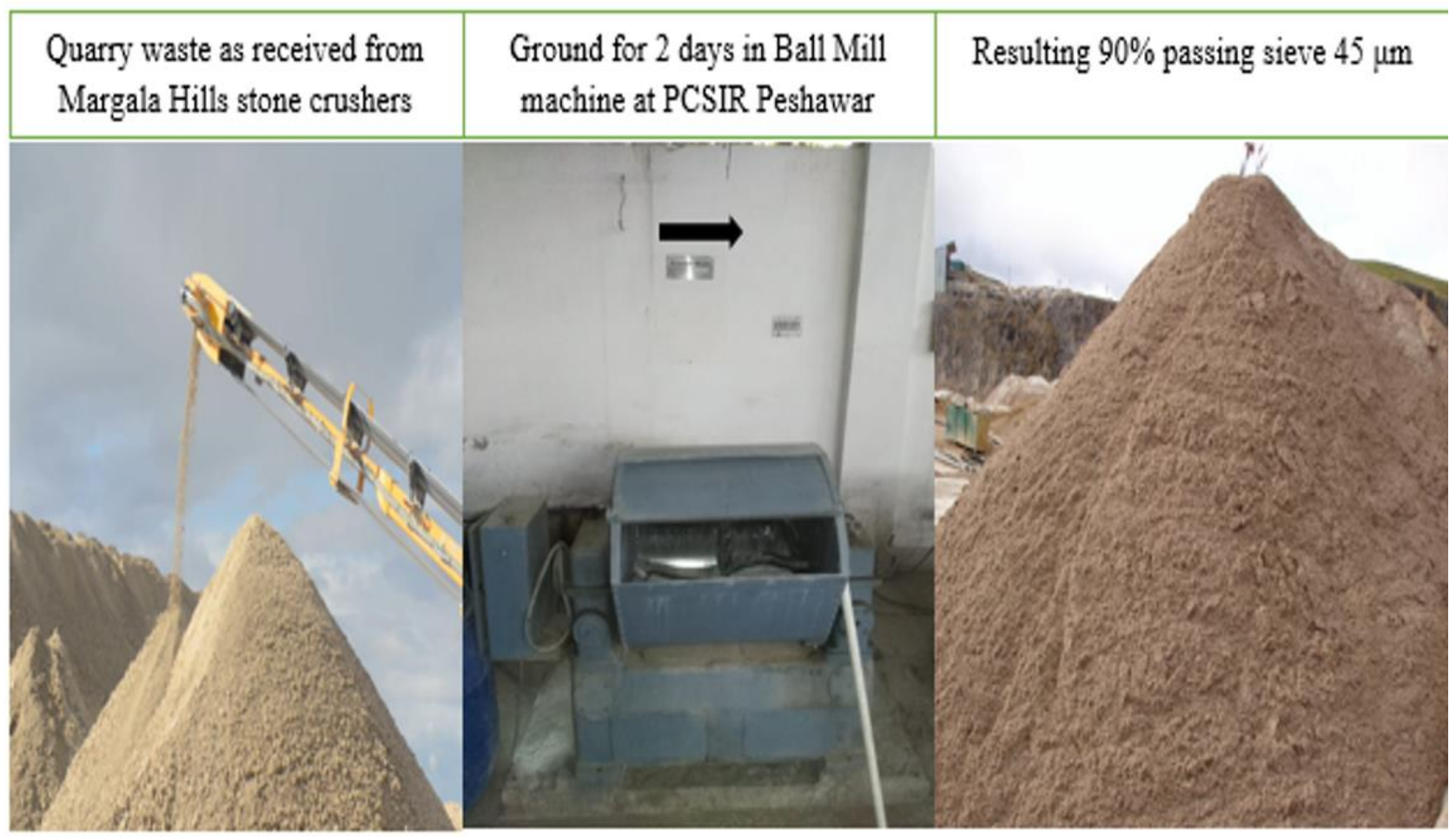

Figure 1. The grinding process of QRD waste.
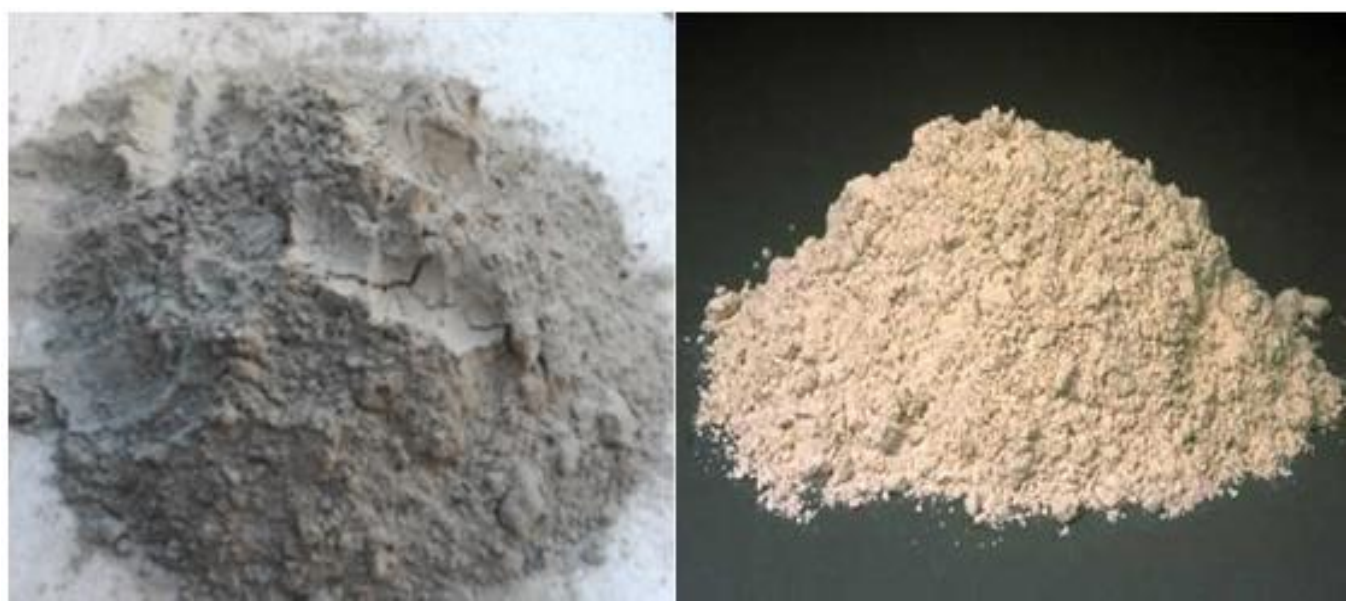

Figure 2. The FA and SG used in the study. 
Table 1. The chemical composition of QRD, SG, and FA from XRF analysis.

\begin{tabular}{cccc}
\hline Material & QRD (\%) & SG (\%) & FA (\%) \\
\hline $\mathrm{SiO}_{2}$ & 9.35 & 34.38 & 58.32 \\
$\mathrm{Al}_{2} \mathrm{O}_{3}$ & 1.64 & 12.98 & 29.5 \\
$\mathrm{Fe}_{2} \mathrm{O}_{3}$ & 1.03 & 1.29 & 1.13 \\
$\mathrm{CaO}$ & 47.13 & 37.33 & 1.57 \\
$\mathrm{MgO}$ & 1.25 & 5.59 & 0.50 \\
$\mathrm{~K}_{2} \mathrm{O}$ & 0.20 & 0.82 & - \\
$\mathrm{Na}_{2} \mathrm{O}$ & - & 0.29 & 0.35 \\
$\mathrm{SO}_{3}$ & 0.08 & 0.23 & 4 \\
$\mathrm{SiO}_{2} / \mathrm{Al}_{2} \mathrm{O}_{3}$ & 5.70 & 2.64 & 2.03 \\
$\mathrm{LOI}($ loss on ignition) & 38.65 & 4.31 & 5.17 \\
\hline
\end{tabular}

Table 2. The chemical and physical characteristics of type II OPC used for control specimens.

\begin{tabular}{cccc}
\hline Chemical Characteristics & Results (\%) & Physical Characteristics & Results \\
\hline $\mathrm{CaO}$ & 64.2 & Specific surface & $322 \mathrm{~m}^{2} / \mathrm{kg}$ \\
$\mathrm{SiO}_{2}$ & 22.0 & Consistency & $30 \%$ \\
$\mathrm{Al}_{2} \mathrm{O}_{3}$ & 5.50 & Initial setting time & $1 \mathrm{~h}: 42 \mathrm{~min}$ \\
$\mathrm{Fe}_{2} \mathrm{O}_{3}$ & 3.50 & Final setting time & $3 \mathrm{~h}: 55 \mathrm{~min}$ \\
$\mathrm{SO}_{3}$ & 2.90 & Specific gravity & 3.5 \\
$\mathrm{MgO}$ & 2.50 & Soundness & No soundness \\
$\mathrm{K}_{2} \mathrm{O}$ & 1.00 & Colour & Grey \\
$\mathrm{Na} \mathrm{N}_{2} \mathrm{O}$ & 0.20 & & \\
$\mathrm{LOI}$ & 0.64 & & \\
\hline
\end{tabular}

The natural river sand from Lawrencepur (near Attock, Pakistan) was used as fine aggregates in the present study. The coarse aggregates (CA) were taken from Margallah quarries (near Taxila, Pakistan). The maximum and minimum size of CA are kept as $20 \mathrm{~mm}$ and $10 \mathrm{~mm}$, respectively, according to the specifications of ASTM C136/C136M-19 [37]. The physical properties of sand and CA are shown in Table 3.

Table 3. The characteristics of sand and CA used in the study.

\begin{tabular}{ccc}
\hline Property & Sand & CA \\
\hline Bulk Density $\left(\mathrm{kg} / \mathrm{m}^{3}\right)$ & 1624 & 1547 \\
Saturated Surface dry water absorption $(\%)$ & 1.25 & 0.80 \\
$10 \%$ fine value $(\mathrm{KN})$ & - & 157 \\
Specific gravity & 2.74 & 2.68 \\
Maximum aggregate size $(\mathrm{mm})$ & 4.75 & 20 \\
Minimum aggregate size $(\mathrm{mm})$ & - & 10 \\
\hline
\end{tabular}

The GPC mix is generally more viscous and has gluey characteristics than the conventional OPC mix due to the high viscosity of $\mathrm{SH}$ and SS solutions [4]. The chemical composition of the SS solution is shown in Table 4. To increase the workability of the fresh ternary blended GPC mixes, a water-reducing admixture commercially identified as Sikament-520 was used as a superplasticizer (SP). The amount of SP was varying in the mixes to achieve a medium range of slump (50 to $89 \mathrm{~mm}$ ) [38] as summarized in Table 5 .

Table 4. The chemical properties of Sodium Silicate (SS) solution.

\begin{tabular}{cc}
\hline Compound & Quantity \\
\hline $\mathrm{Na}_{2} \mathrm{O}$ & $8.93 \%$ \\
$\mathrm{SiO}_{2}$ & $29.8 \%$ \\
Water & $61.78 \%$ \\
Density & $1400 \mathrm{~kg} / \mathrm{m}^{3}$ \\
\hline
\end{tabular}


Table 5. The composition and proportions of mixes used in the study.

\begin{tabular}{|c|c|c|c|c|c|c|c|c|c|c|c|c|c|c|c|c|c|c|c|c|c|}
\hline \multirow[b]{2}{*}{$\begin{array}{l}\dot{2} \\
z \\
\vdots \\
0 \\
0\end{array}$} & \multirow[b]{2}{*}{ 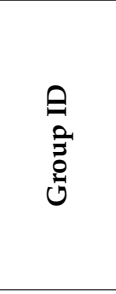 } & \multicolumn{8}{|c|}{ Mixture Proportions } & \multicolumn{12}{|c|}{ Concrete Mixture Quantity (kg/m3) } \\
\hline & & ن & $\stackrel{\mathbb{S}}{0}^{0}$ & نे & $\begin{array}{l}\stackrel{0}{0} \\
\text { â }\end{array}$ & 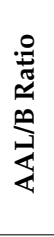 & 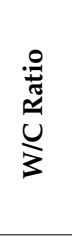 & 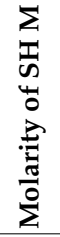 & 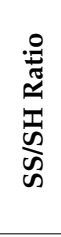 & $\infty$ & $u$ & $\mathbb{I}$ & U & 党 & 峦 & $\infty$ & $n$ & 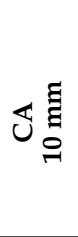 & Ч & के & $\frac{\grave{n}}{3}$ \\
\hline 1 & OPC & 100 & - & - & - & - & 0.35 & - & - & 400 & 400 & - & - & - & - & - & 680 & 751 & 340 & 10 & 140 \\
\hline 2 & GPC-A & - & 50 & 50 & 0 & 0.5 & - & 12 & 1.5 & 400 & - & 200 & 200 & 0 & 80 & 120 & 680 & 751 & 340 & 10 & 35 \\
\hline 3 & GPC-B & - & 50 & 45 & 5 & 0.5 & - & 12 & 1.5 & 400 & - & 200 & 180 & 20 & 80 & 120 & 680 & 751 & 340 & 12 & 35 \\
\hline 4 & GPC-C & - & 50 & 40 & 10 & 0.5 & - & 12 & 1.5 & 400 & - & 200 & 160 & 40 & 80 & 120 & 680 & 751 & 340 & 14 & 35 \\
\hline 5 & GPC-D & - & 50 & 35 & 15 & 0.5 & - & 12 & 1.5 & 400 & - & 200 & 140 & 60 & 80 & 120 & 680 & 751 & 340 & 14.5 & 35 \\
\hline 6 & GPC-E & - & 50 & 30 & 20 & 0.5 & - & 12 & 1.5 & 400 & - & 200 & 120 & 80 & 80 & 120 & 680 & 751 & 340 & 14.5 & 35 \\
\hline
\end{tabular}

Note: W (Water): B (Binder); C (Cement): OPC (Ordinary Portland Cement); AAL (Alkaline Activator Solution); QRD (Quarry Rock Dust); SG (Ground Granulated Blast Furnace Slag); FA (Fly Ash); SH (Sodium Hydroxide); SS (Sodium Silicate); M(molarity); SP (Superplasticizers); S (Sand); CA (Coarse Aggregates).

The AAS to binder (AAS/B) ratio, defined as the sum of their ratio by mass to the total mass of binder, was kept constant for all mixes at 0.50 . In the binder, three types of source materials, FA, SG, and QRD, were used. The AAS/B was calculated using Equation (1) [36] as follows:

$$
\frac{\mathrm{AAS}}{\mathrm{B}}=\frac{\mathrm{SH}+\mathrm{SS}}{\mathrm{QRD}+\mathrm{FA}+\mathrm{SG}}=0.50
$$

\subsection{Mix Types, Proportions, and Preparation of Specimens for Tests}

A total of 5 mix types were prepared to study the effect of QRD incorporation on QFS-GPC mixes. One mix type is prepared with the OPC to be taken as a reference/control mix. The five QFS-GPC mixes were prepared with varying QRD ratios by weight. The mixed proportions of materials used in this study are shown in Table 5. All the QFS-GPC specimens were prepared with the same molarity of $\mathrm{SH}, \mathrm{AAS} / \mathrm{B}$ ratio, and SS/SH ratio. The labels GPC-A, GPC-B, GPC-C, GPC-D, and GPC-E represent different specimen groups of design mix. In all GPC mixes, FA was kept constant, and SG was replaced by QRD at different ratios, viz., $0 \%, 5 \%, 10 \%, 15 \%$, and $20 \%$ in groups GPC-A, GPC-B, GPC-C, GPC-D, and GPC-E, respectively.

The alkaline activating solution (AAS) was prepared by mixing SH and SS in predetermined quantities. The AAS played a significant role in the geopolymerization process. The $\mathrm{SH}$ solution of $12 \mathrm{M}$ molarity was prepared by mixing $\mathrm{NaOH}$ pellets having $98 \%$ purity in water. Since an exothermic reaction takes place from the preparation of $\mathrm{SH}$ solution, a significant amount of heat was produced during this preparation. The $\mathrm{SH}$ solution, therefore, was prepared $24 \mathrm{~h}$ before its mixing with SS solution to develop AAS. The SH and SS solutions were mixed at least $30 \mathrm{~min}$ before their application. The ratio between SS and $\mathrm{SH}$ was kept constants for all the mixes at 1.5.

A mechanical mixer of $0.15-\mathrm{m}^{3}$ capacity with a speed of $20 \mathrm{rev} / \mathrm{min}$ was used for mixing the ingredients. Firstly, all the ingredients including FA, QRD, SG, sand, and CA were dry mixed for 2 min to ensure uniformity of the mixture. Then, AAS, SP, and extra water were added gradually as required and mixing is continued for another $3 \mathrm{~min}$. The freshly mixed concrete was then instantly cast into three different molds, i.e., cubes $(150 \mathrm{~mm} \times 150 \mathrm{~mm} \times 150 \mathrm{~mm})$ for compressive strength, cylinders $(150 \mathrm{~mm} \times 300 \mathrm{~mm})$ for splitting tensile strength, and prisms $(100 \mathrm{~mm} \times 100 \mathrm{~mm} \times 500 \mathrm{~mm})$ for flexural strength tests. A total of 360 specimens comprising 180 cubes, 108 cylinders, and 72 prisms were cast. For each testing age, three specimens were cast, and their average value was taken after testing for the results and discussion. All the freshly prepared specimens were kept in a laboratory room under ambient conditions. After $24 \mathrm{~h}$, the samples were de-molded, then QFS-GPC and OPC specimens were kept in the open sunlight and the curing tank respectively until the day of testing. 
The fresh mix property, i.e., workability of OPC and GPC mixes, was investigated by using a slump cone test following the ASTM C143/C143M-20 [38]. The mechanical properties of each mix under ambient curing conditions are assessed by cubes for the compressive strength following BS EN 12390-3:2019 [39], cylinders for the splitting tensile strength following ASTM C496/C496M-17 [40], and prisms for the flexural strength test following ASTM C78/C78M-21 [41], using a universal testing machine (UTM) of $4000 \mathrm{kN}$ capacity. For ascertaining properties at elevated temperature, cubic specimens of dimension $150 \mathrm{~mm} \times 150 \mathrm{~mm} \times 150 \mathrm{~mm}$ were prepared for each mix type. After 56 days of ambient curing, the specimens were heated in an automatic electric furnace of $1000{ }^{\circ} \mathrm{C}$ capacity under two temperature settings, i.e., $400^{\circ} \mathrm{C}$ and $800^{\circ} \mathrm{C}$, for $1 \mathrm{~h}$ following ASTM E 11920 [42]. After heating to the required temperature, the specimens were cooled at room temperature. Then, the residual compressive strength was determined following BS EN 12390-3:2019 [39]. The weight of each cubic specimen before and after exposure to elevated temperature was obtained to find the weight loss due to exposure at the relevant elevated temperature. The reaction phases of OPC and QFS-GPC specimens were identified by X-ray diffraction test.

\section{Results and Discussion}

The results and discussion of the present research study include the fresh property, i.e., workability, the mechanical properties, i.e., compressive, split tensile, flexural strength, residual compressive strength, and weight loss, and the X-ray diffractions of the OPC and QFS-GPC specimens are described.

\subsection{Workability}

GPC has sticky characteristics due to the high viscosity of the SH and SS solutions [11]. Therefore, the workability of the GPC mixes is generally lower than the conventional OPC mixes. The GPC mixes can be compacted well by using vibrators, even for the concrete with relatively low slump values. Therefore, keeping in view the compaction conditions, GPC can be classified into three categories depending upon the slump values achieved, i.e., highly workable, medium workable, and low workable [21]. The GPC mixture is considered highly workable when it achieves a workability of $90 \mathrm{~mm}$ and over. When the workability of the GPC mixture is between $50 \mathrm{~mm}$ and $89 \mathrm{~mm}$, it is considered as medium workable, while slump values below $50 \mathrm{~mm}$ are classified as low workable. In the present study, a medium workable mix (of slump value between 50 and $89 \mathrm{~mm}$ ) was considered as the target slump. It can be observed from Figure 3 that the slump values of the control mix samples have an average value of $85 \mathrm{~mm}$. The average slump values of the GPC-A, GPC-B, GPC-C, GPC-D, and GPC-E mixes were observed as $75 \mathrm{~mm}, 75 \mathrm{~mm}, 80 \mathrm{~mm}$, $73 \mathrm{~mm}$, and $70 \mathrm{~mm}$, respectively. It was observed during the test that the workability of QFS-GPC decreased gradually by increasing the replacement levels of QRD from 5\% to $20 \%$. Therefore, the target slump values (medium workability [21]) of the mix groups were achieved by gradually increasing dosages of SP from GPC-A to GPC-E as mentioned in Table 5 while keeping the amount of water added the same in all the QFS-GPC mixes. It was also confirmed from the previous studies that the use of QRD up to $50 \%$ as replacement of sand in both OPC and GPC mixes reduced the workability [24]. In QFS-GPC mixes, the incorporation of QRD has negative effect on the workability. It results in decreasing the workability of the mix considerably, and handling become difficult during the placement of fresh QFS-GPC by incorporation of QRD. Hence, to attain the medium workability standard [21], extra water and superplasticizer were used. 


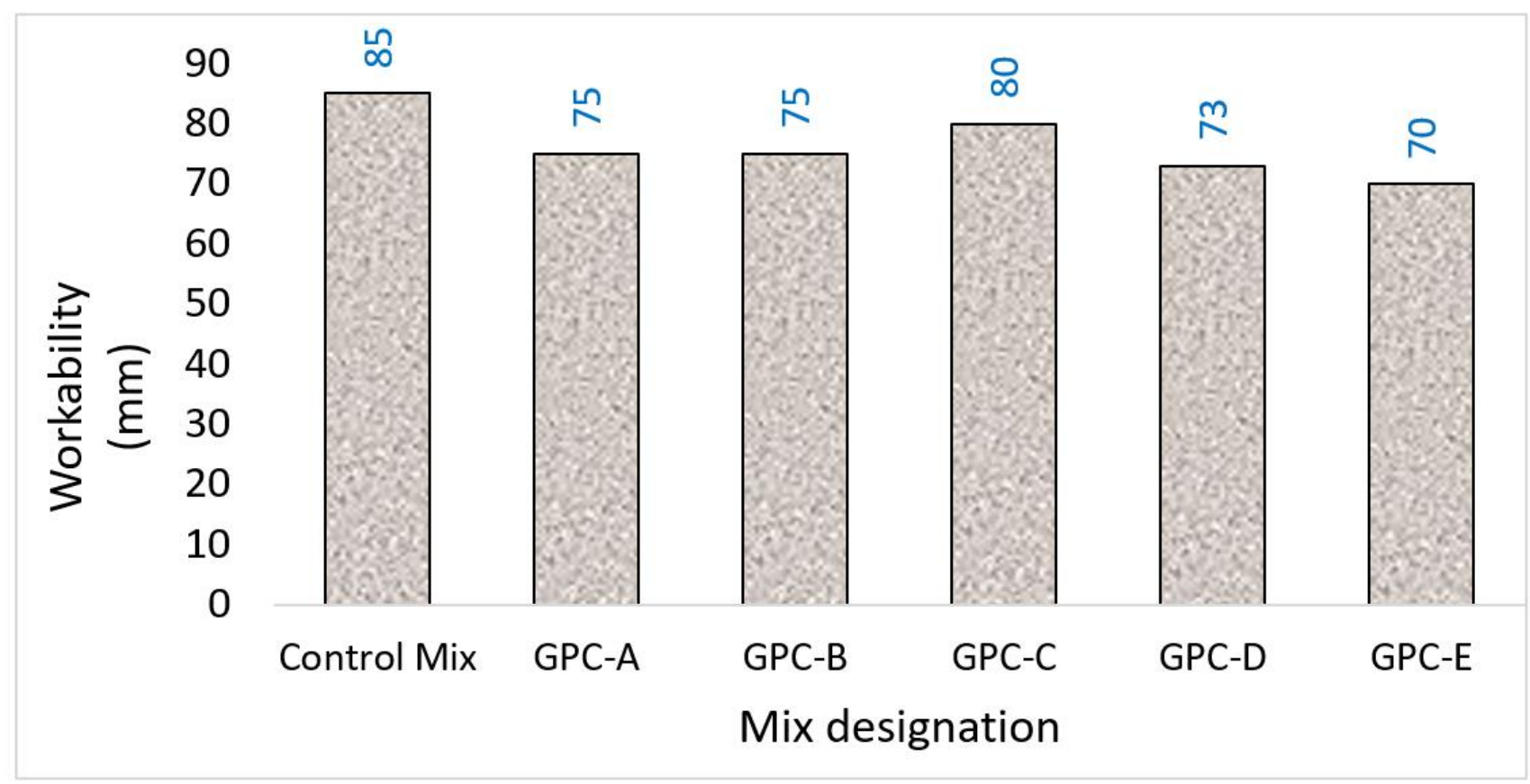

Figure 3. The slump values of control (OPC) and QFS-GPC mixes to the target slump (medium workable) after the addition of the varying amount of SP.

\subsection{Compressive Strength}

Compressive strength is one of the significant properties of concrete, which is linked with other properties as well. It is generally used to ascertain the mechanical strength and durability-related characteristics of concrete structural elements. The compressive strength tests were carried out on cubical specimens $(150 \times 150 \times 150 \mathrm{~mm})$ at the ages of 7,28 , and 56 days using a universal testing machine of $4000 \mathrm{kN}$ capacity following BS EN 12390-3: 2019 [39]. From Figure 4, it can be observed that there was an increase in the compressive strength in all the mix samples from 7 to 28 and 56 days. The replacement of QRD with SG up to $15 \%$ (GPC-D) has shown the maximum overall strength of $33.55 \mathrm{MPa}$ at 56 days. However, the compressive strength was decreased when the QRD content was further increased from $15 \%$ to $20 \%$, i.e., in the GPC-E mix, which showed $22.77 \mathrm{MPa}$ strength at 56 days, nearly $24 \%$ and $32 \%$ less than the control (OPC) and GPC-D mixes, respectively. For the control (OPC) mix, increments of $23 \%$ and $19 \%$ in the compressive strength were observed from 7 to 28 and 28 to 56 days, respectively, with an overall increase in the strength of $46 \%$ from 7 to 56 days. Meanwhile, in GPC-A, GPC-B, GPC-C, GPC-D, and GPC-E, increments of $40 \%, 32 \%, 33 \%, 23 \%$, and $34 \%$, respectively, were observed in the strength from 7 to 28 days, with an overall increase of $49 \%, 48 \%, 47 \%, 31 \%$, and $57 \%$, respectively, from 7 to 56 days under ambient curing conditions. The target compressive strength of $30 \mathrm{MPa}$ (of control OPC concrete specimen) was accomplished by GPC-B (30.44 MPa), GPC-C (32.22 MPa), and GPC-D (33.55 MPa) with 50\% FA and SG/QRD contents of 45/5\%, $40 / 10 \%$, and $35 / 15 \%$, respectively. It can be observed that the replacement of SG beyond $15 \%$ with QRD has a negative effect on the compressive strength of QFS-GPC. Several additions/replacements in geopolymer concrete can be used to enhance its mechanical properties. Melamine fibers were used in the literature shows around $10 \%$ enhancement in strength from $5 \%$ fiber addition [43]. 


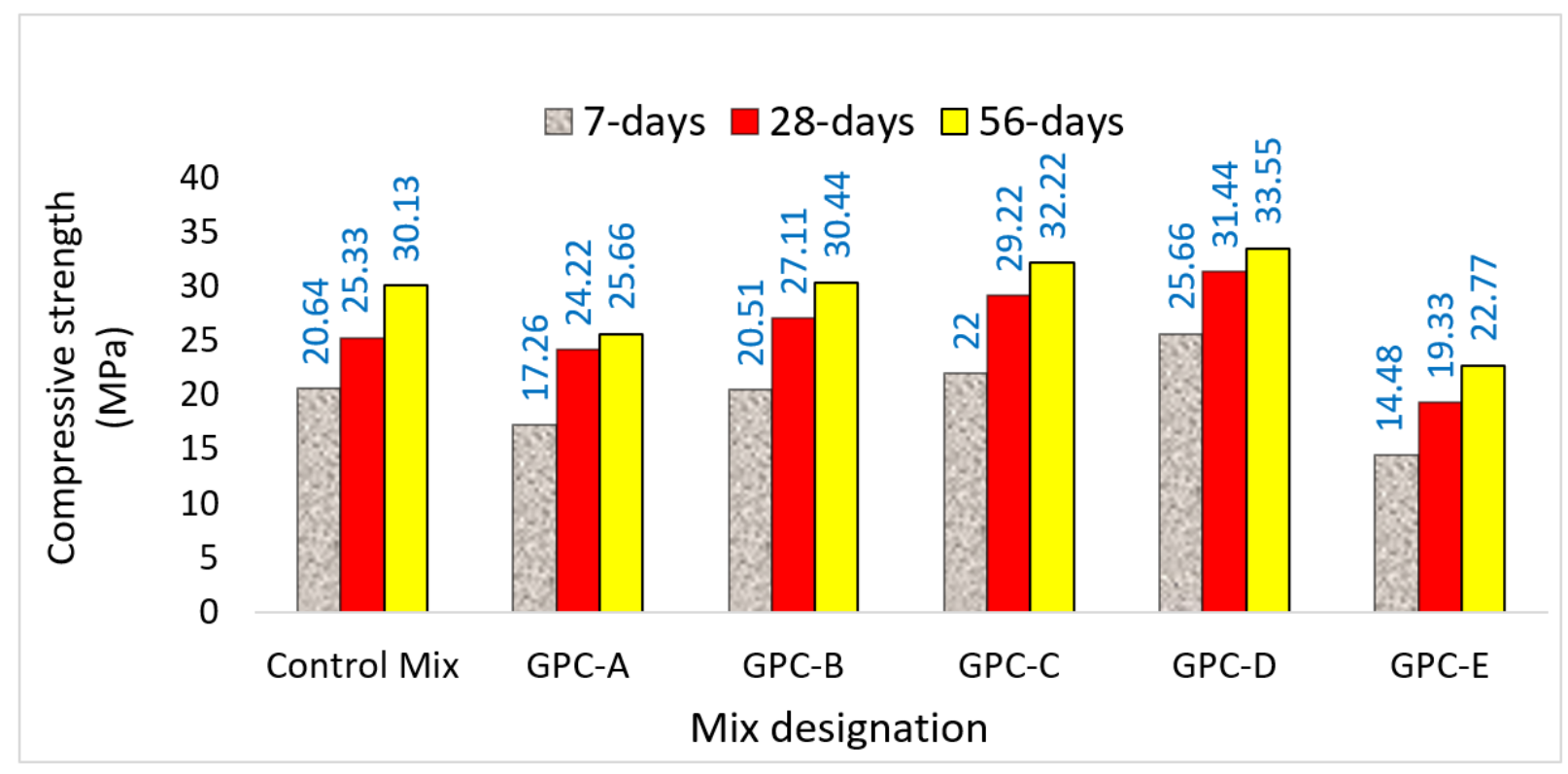

Figure 4. The compressive strength values of control (OPC) and QFS-GPC samples at 7, 28, and 56 days.

The increase in the strength can be attributed to the content of calcium oxide [44]. The contents of $\mathrm{CaO}$ in FA, SG, and QRD used in present research study are $2 \%, 37.33 \%$, and $47.13 \%$, respectively (Table 1 ). There is a significant role of $\mathrm{CaO}$ content in the polymerization process of GPC mixtures. The $\mathrm{CaO}$ content aids in accelerating the polymerization process at ambient as well as at low temperatures $[45,46]$. In the present study, the $\mathrm{CaO}$ contents were increased with the replacement of SG by QRD, which has the maximum $\mathrm{CaO}$ content $(47.13 \%)$ among all the source or binder materials. Therefore, the addition of $\mathrm{CaO}$ (by replacing SG with QRD) in the GPC matrix increased the compressive strength [46] due to the pore size reduction of specimens. However, beyond the 15\% replacement of SG by QRD, a significant reduction in strength was observed. This reduction in the compressive strength can be due to excess of $\mathrm{CaO}$ contents in QRD and the partial hydration of $\mathrm{CaO}$ in the alkaline medium to form $\mathrm{Ca}(\mathrm{OH})_{2}$ [45] and incomplete geopolymerization [46,47]. This trend of decrease in strength can be due to the addition of extra water and superplasticizer to maintain workability.

\subsection{Splitting Tensile Strength}

Splitting tensile strength is an engineering property of concrete that is used in design features of construction elements such as those associated with the beginning and propagation of cracks, anchorage, and shear strength in structural members [3]. The splitting tensile strength not only represents the true tensile strength but also depicts the failure patterns of specimens under the action of loads (splitting load). The tensile strength test was carried out following ASTM C496/C496M-17 [40] on cylindrical specimens $(150 \times 300 \mathrm{~mm})$ at the ages of 7, 28, and 56 days after casting, and results are shown in Figure 5.

It can be observed from the figure that the tensile strength is increasing for QFS-GPC samples until 15\% replacement of SG by QRD (GPC-D); while a further increase in QRD, i.e., 20\% (GPC-E), showed a decrease in tensile strength. From the test results at 7 days, the specimens of OPC, GPC-A, GPC-B, GPC-C, GPC-D, and GPC-E depicted 1.57 MPa, 1.45 $\mathrm{MPa}, 1.49 \mathrm{MPa}, 1.56 \mathrm{MPa}, 1.66 \mathrm{MPa}$, and 1.09 $\mathrm{MPa}$ split tensile strengths, respectively. Only the samples of GPC-D had shown higher early (7 days) and later age (28 and 56 days) tensile strengths than the OPC control specimens. The 7 days tensile strengths of GPC-A, GPC-B, GPC-C, and GPC-E are 7.6\%, 5\%, 1\%, and 31\%, respectively, lower than the control mix sample, while GPC-D has a 5.7\% higher tensile strength than the control specimen at 7 days. However, the tensile strength tests at 28 and 56 days depicted $4.8 \%$ and $6.6 \%$, respectively, lower strengths of GPC-D than the control OPC mix, which shows slightly 
less than the target control OPC specimen; however, this can be further improved by incorporating fibers. Albeit the increment in the tensile strength is observed from mix GPC-A to GPC-D. The GPC-D mix with 15\% QRD has $14.48 \%$ more split tensile strength than mix GPC-A having $0 \%$ QRD contents.

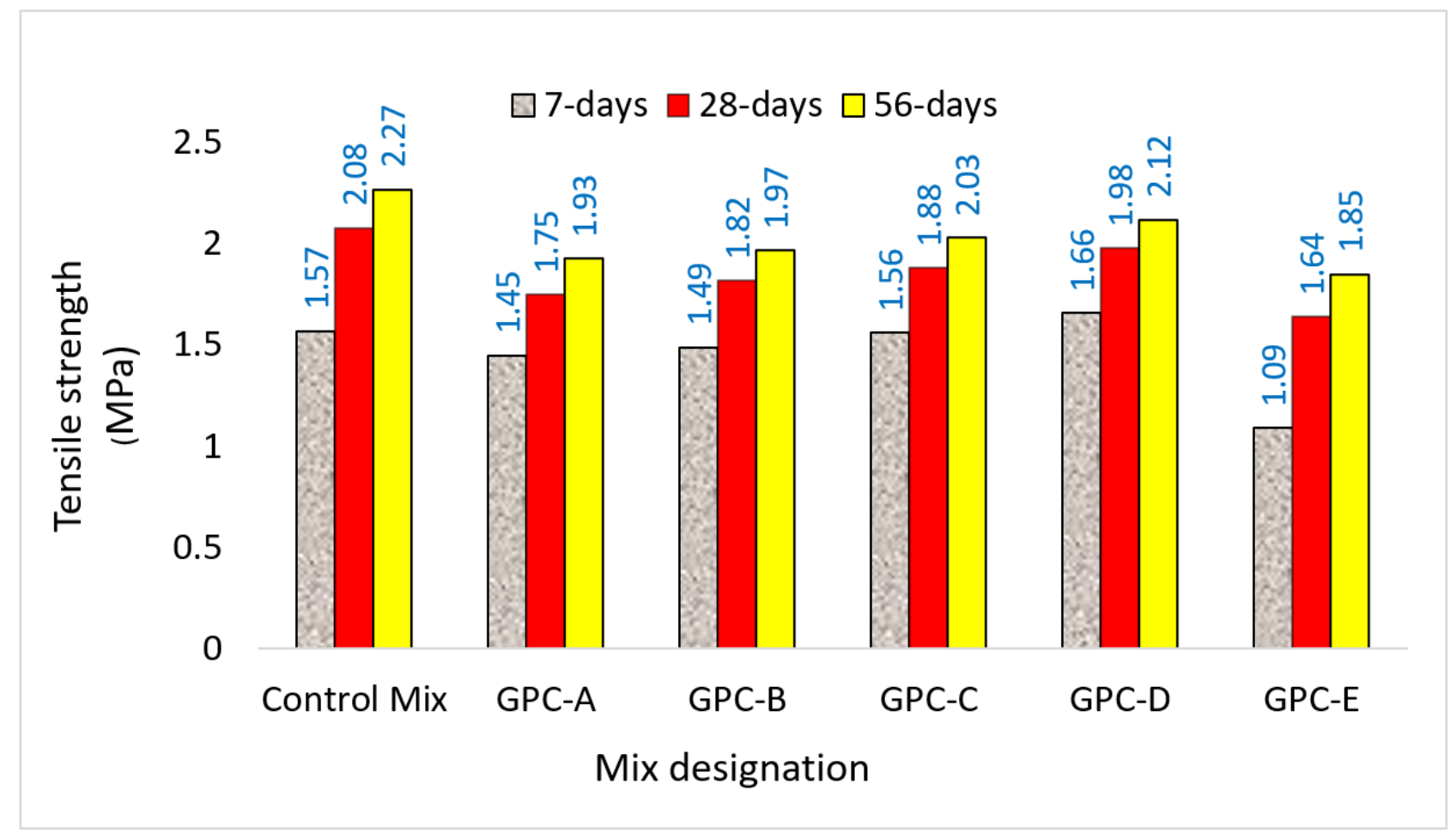

Figure 5. The splitting tensile strength of control OPC and QFS-GPC samples at 7, 28, and 56 days.

At the age of 28 days, the tensile strength for the control OPC mix and GPC-A to E were observed as $1.98 \mathrm{MPa}, 1.75 \mathrm{MPa}, 1.82 \mathrm{MPa}, 1.88 \mathrm{MPa}, 2.08 \mathrm{MPa}$, and $1.64 \mathrm{MPa}$, respectively. There was a decrease in the tensile strength of GPC-A to E of $16 \%, 12.5 \%$, $9.6 \%, 4.8 \%$, and $21 \%$, respectively, from the strength of the control OPC mix. However, GPC-D has the least difference (less than 5\%) from the strength of the OPC specimen. Among the QFS-GPC mixes, the tensile strength of mix GPC-D is 13.14\% more than GPC-A. Geopolymer concrete performs better in terms of compressive strength. However, the tensile strength of GPC depends on the initiation of cracks in the matrix. The previous study has reported that geopolymer concrete performs better in terms of tensile strength as compared to the ordinary Portland cement concrete $[36,48]$. Another study reported that the ACI standard design code better predicts the tensile strength of geopolymer concrete. Use of up to $30 \%$ GGBS in geopolymer concrete increased the splitting tensile strength [36]. Similar upward trend in tensile strength in the current study was observed with up to $15 \% \mathrm{QRD}$ in geopolymer concrete.

At the age of 56 days, the splitting tensile strengths of the control mix and GPC-A to E were observed as $2.27 \mathrm{MPa}, 1.93 \mathrm{MPa}, 1.97 \mathrm{MPa}, 2.03 \mathrm{MPa}, 2.12 \mathrm{MPa}$, and $1.85 \mathrm{MPa}$, respectively. The tensile strengths of the GPC-A to E mixes were less than the control OPC mix by $15 \%, 13 \%, 10.6 \%, 6.6 \%$, and $18.5 \%$, respectively. There was an improvement in the tensile strength of all the QFS-GPC specimens from 7 to 28 and 56 days; however, the tensile strength has been observed to be less than the conventional concrete specimens at all ages except for GPC-D, which has slightly more strength at 7 days than the control OPC specimen. Furthermore, the trends of increases in tensile strengths are similar to that of the compressive strength results, where up to $15 \%$ replacement of SG by QRD has improved the strength. The maximum tensile strength achieved by any QFS-GPC specimen was attained by GPC-D (2.12 MPa), which is slightly less $(6.6 \%)$ than the control OPC specimen at 
56 days. The improvement in the strength of the QFS-GPC specimens at all ages was due to an increase of calcium-bearing mixtures in the dissolution binders, which yielded a reaction product from both SG and FA [49]. The QRD has maximum CaO content (47\%) among all the source materials. The increase in strength with increasing the replacement levels of QRD is due to the increased $\mathrm{CaO}$ contents which reduce the pore sizes in the geopolymer matrix consequently improving mechanical properties. However, the replacement level of QRD beyond 15\% decreased the tensile strength due to the incomplete hydration of $\mathrm{CaO}$ contents of QRD present in excess quantity $(47 \%)$ in the alkaline medium to form $\mathrm{Ca}(\mathrm{OH})_{2}$ [45]. The tensile strength also reduces due to the deficient geopolymerization process [47].

\subsection{Flexural Strength}

The flexural strength of the OPC and GPC specimens was evaluated by the third point loading test on prism specimens $(100 \times 100 \times 500 \mathrm{~mm})$ following ASTM C78/C78M-21 [41]. It was performed to find the modulus of rupture (MOR) of prism specimens at the age of 28 and 56 days. The shape and texture of binders and aggregates can affect the flexural strength of concrete [28]. Kaosol (2010) reported that the impact of binder and aggregate shape and texture is more obvious in the modulus of rupture test than the cylindrical split tensile or uniaxial compression tests [49]. He ascribed that the presence of stress gradient behavior delays the process of cracking specimens, which leads to the ultimate failure. The results of the flexural strength test of all the groups are shown in Figure 6. The trend of increasing strength observed in the GPC mixes is similar to the compressive and tensile strength results. The flexural strength of the OPC $\operatorname{mix}$ is $2.62 \mathrm{MPa}$ at 28 days, while the GPC-A, GPC-B, GPC-C, GPC-D, and GPC-E have 2.45 MPa, 2.53 MPa, 2.64 MPa, 2.87 MPa, and $2.31 \mathrm{MPa}$, respectively. The control OPC mix has $6.49 \%, 3.44 \%$, and $11.83 \%$ more flexural strength at 28 days than the GPC-A, GPC-B, and GPC-E, respectively, whereas GPC-C and GPC-D have $0.64 \%$ and $6.11 \%$ more flexural strength than the control OPC mix specimens at 28 days. It can be observed from Figure 6 that the flexural strength of GPC-D is the maximum among all the OPC and GPC mix specimens at 56 days. The flexural strength of the GPC-D mix is $15 \%, 10 \%, 7 \%$, and $20 \%$ higher than the GPC-A, GPC-B, GPC-C, and GPC-E, respectively. The control OPC mix has 14.41\%, 11.03\%, 7.63\%, and $4.24 \%$ higher flexural strength than GPC-E, GPC-A, GPC-B, and GPC-C, respectively.

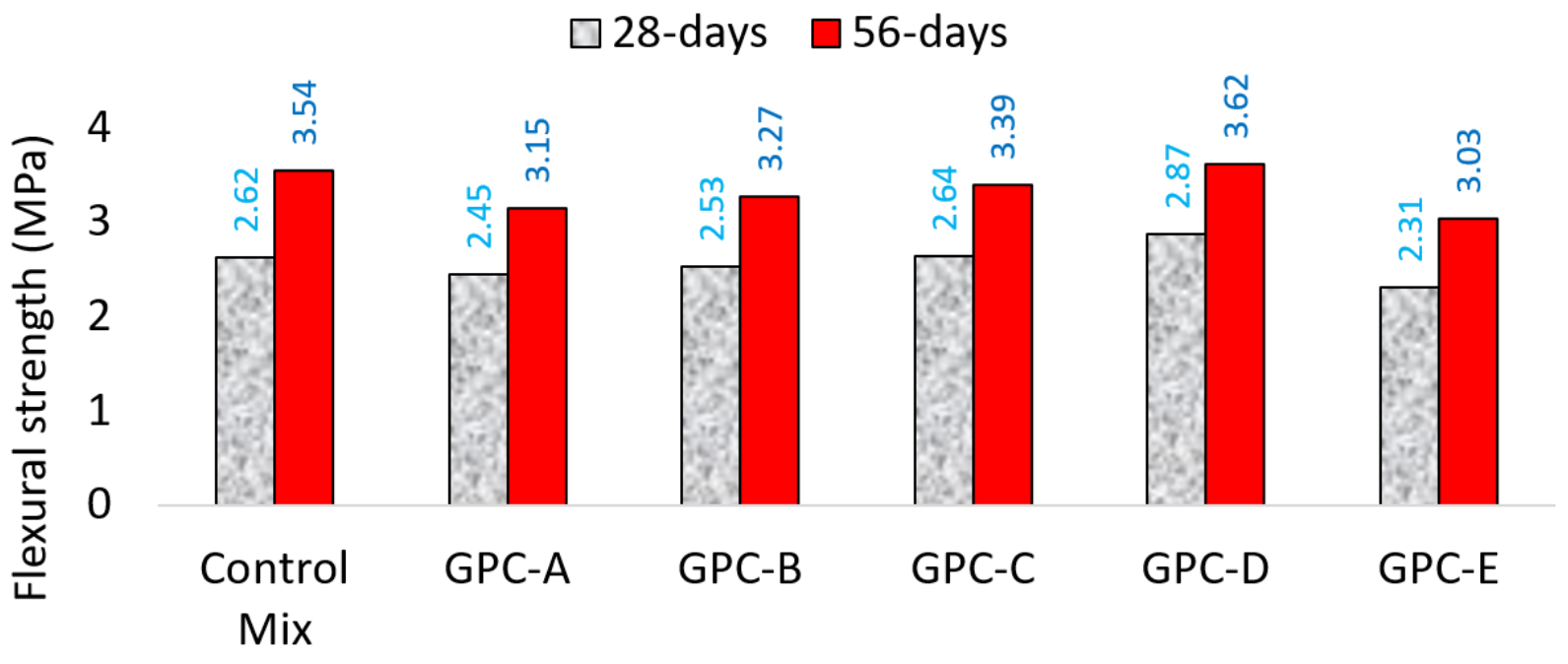

\section{Mix designation}

Figure 6. The flexural strength of the control (OPC) and QFS-GPC specimens at 28 and 56 days.

The replacement of QRD up to $15 \%$ has resulted in increasing the flexural strength of all GPC mix specimens. The flexural strength of GPC-B, GPC-C, and GPC-D at 56 days 
is $3.81 \%, 7.62 \%$, and $14.92 \%$ higher than the GPC-A (without QRD content). The rough and angular texture crushed particles such as QRD [50] produce the concrete with higher flexural strength than with the rounded shape constituents. The physical and chemical bond developed by the angular shape particles is stronger than the bond developed by the rounded particles [49,51]. Bakri et al. (2013) and Rao et al. (2012) also found that the replacement of QRD with sand increases the strength properties of concrete [52,53]. A reduction in the flexural strength was observed with increasing the QRD content beyond $15 \%$ (GPC-E). This decrease in flexural strength is due to the incomplete hydration of excess lime $(\mathrm{CaO})$ contents (present in $\mathrm{QRD})$ in the alkaline medium to make $\mathrm{Ca}(\mathrm{OH})_{2}$ and an incomplete geopolymrization process [44,45,47].

\subsection{Residual Compressive Strength and Weight Loss after Heating to $400^{\circ} \mathrm{C}$ and $800^{\circ} \mathrm{C}$}

Geopolymers had shown better mechanical properties at lower exposure temperatures. However, the reduction increases after high temperature exposure [54]. For ascertaining properties at elevated temperature, cubic specimens (of dimensions $150 \mathrm{~mm} \times 150 \mathrm{~mm} \times 150 \mathrm{~mm}$ ) were prepared for each mix type. After 56 days of ambient curing, the specimens were heated in an automatic controlled electric furnace of $1000^{\circ} \mathrm{C}$ capacity under two temperature settings, i.e., $400{ }^{\circ} \mathrm{C}$ and $800{ }^{\circ} \mathrm{C}$, for $1 \mathrm{~h}$ following ASTM E 119-20 [49]. After heating to the required temperature, the specimens were cooled at room temperature. Then, the residual compressive strength was determined following BS EN 12390-3: 2019 [39]. The weight of each cubic specimen before and after exposure to elevated temperature was obtained to find the weight loss due to exposure at the relevant elevated temperature. The residual compressive strength of the test specimens is shown in Figure 7. The results for the specimens heated at $400{ }^{\circ} \mathrm{C}$ show that the control OPC mix has $38.40 \%, 41.55 \%, 49.71 \%$, $49.79 \%$, and $50.83 \%$ more residual compressive strength than GPC-A, GPC-B, GPC-C, GPC-D, and GPC-E, respectively. Among the GPC mixes, GPC-A has 4.95\%, 6.98\%, 7.09\%, and $8.78 \%$ higher residual compressive strength than GPC-B, GPC-C, GPC-D, and GPC-E, respectively, at $400{ }^{\circ} \mathrm{C}$. The residual compressive strength of the GPC mixes, i.e., GPCA, GPC-B, GPC-C, GPC-D, and GPC-E, after heating at $800^{\circ} \mathrm{C}$ was further decreased by $14.41 \%, 12.32 \%, 3.5 \%, 2.07 \%$, and $15.9 \%$, respectively, compared to the compressive strength of their respective specimens at $400{ }^{\circ} \mathrm{C}$. The residual compressive strength test results of the specimens exposed to elevated temperature are in agreement with the previous research. The compressive strength significantly decreased after the temperature escalated from 200 to $800{ }^{\circ} \mathrm{C}$. The basalt-reinforced geopolymer foams showed better properties after exposure to high temperature. The compressive strength significantly improved after exposure to temperatures higher than $600{ }^{\circ} \mathrm{C}$ [55].

The test results show that strength is decreasing persistently by the replacement of SG with QRD, and the minimum residual strength was observed in the GPC-E specimens with $20 \%$ QRD content.

The test results for the weight loss of all types of mixes are shown in Figure 8. It can be observed that the control OPC mix is the most fire-resistant since it has the lowest weight loss among all the mixes. The weight loss in the QFS-GPC mixes was observed to be more with a rise in temperature. Among the QFS-GPC mixes, GPC-A has the lowest weight loss as compared to the other QFS-GPC mixes. Geopolymers revealed the reduction in the mechanical strength when exposed to elevated temperatures [56,57]. It is in agreement with the existing literature. Blended ash geopolymer concrete in the previous research showed a decrease in strength at higher exposure temperatures $\left(400-800^{\circ} \mathrm{C}\right)$. However, the strength increased up to 200. It could be attributed to the stable mix of blended ash geopolymer as compared to the ordinary Portland cement concrete [58]. At $400{ }^{\circ} \mathrm{C}$, the weight loss of the GPC-A specimen was $29.55 \%$ higher than the OPC mix. Among the QFS-GPC specimens, the weight loss of GPC-A was 7.27\%, 10.45\%, 58.64\%, and 70\% lower than the GPC-B, GPC-C, GPC-D, and GPC-E specimens, respectively. At $800^{\circ} \mathrm{C}$ temperature, the weight loss of GPC-A was $20.35 \%$ higher than the control mix. The QFS-GPC mixes, GPC-B, GPC-C, GPC-D, and GPC-E have 2.36\%, 3.64\%, 28.73\%, and 33.64\% higher weight loss than the 
GPC-A specimens, respectively. It can be observed that the weight loss of the QFS-GPC specimens increased with the increase in QRD content from $0 \%$ to $20 \%$.

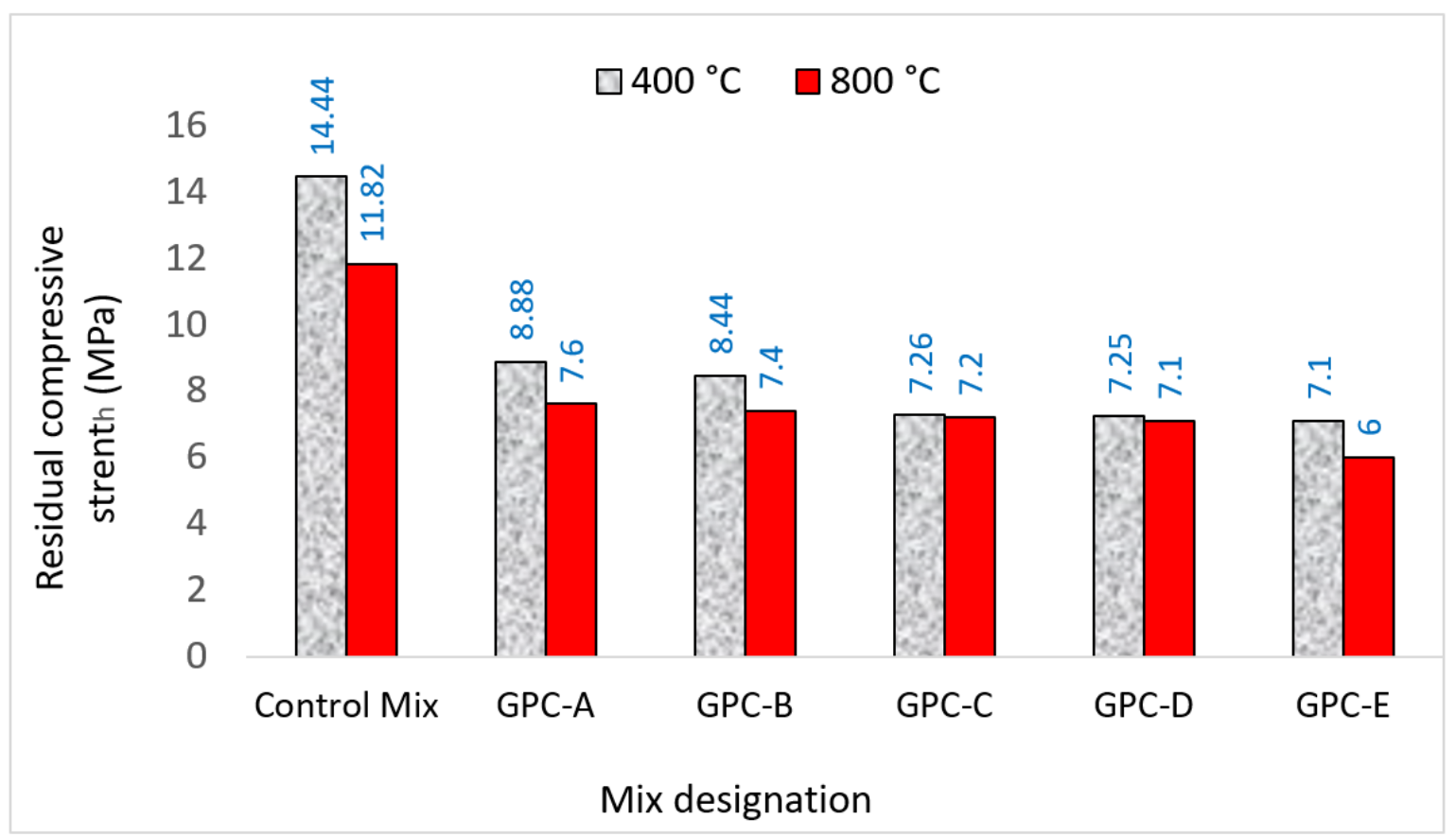

Figure 7. The residual compressive strength of OPC and QFS-GPC specimens after exposure to $400{ }^{\circ} \mathrm{C}$ and $800{ }^{\circ} \mathrm{C}$ temperatures.

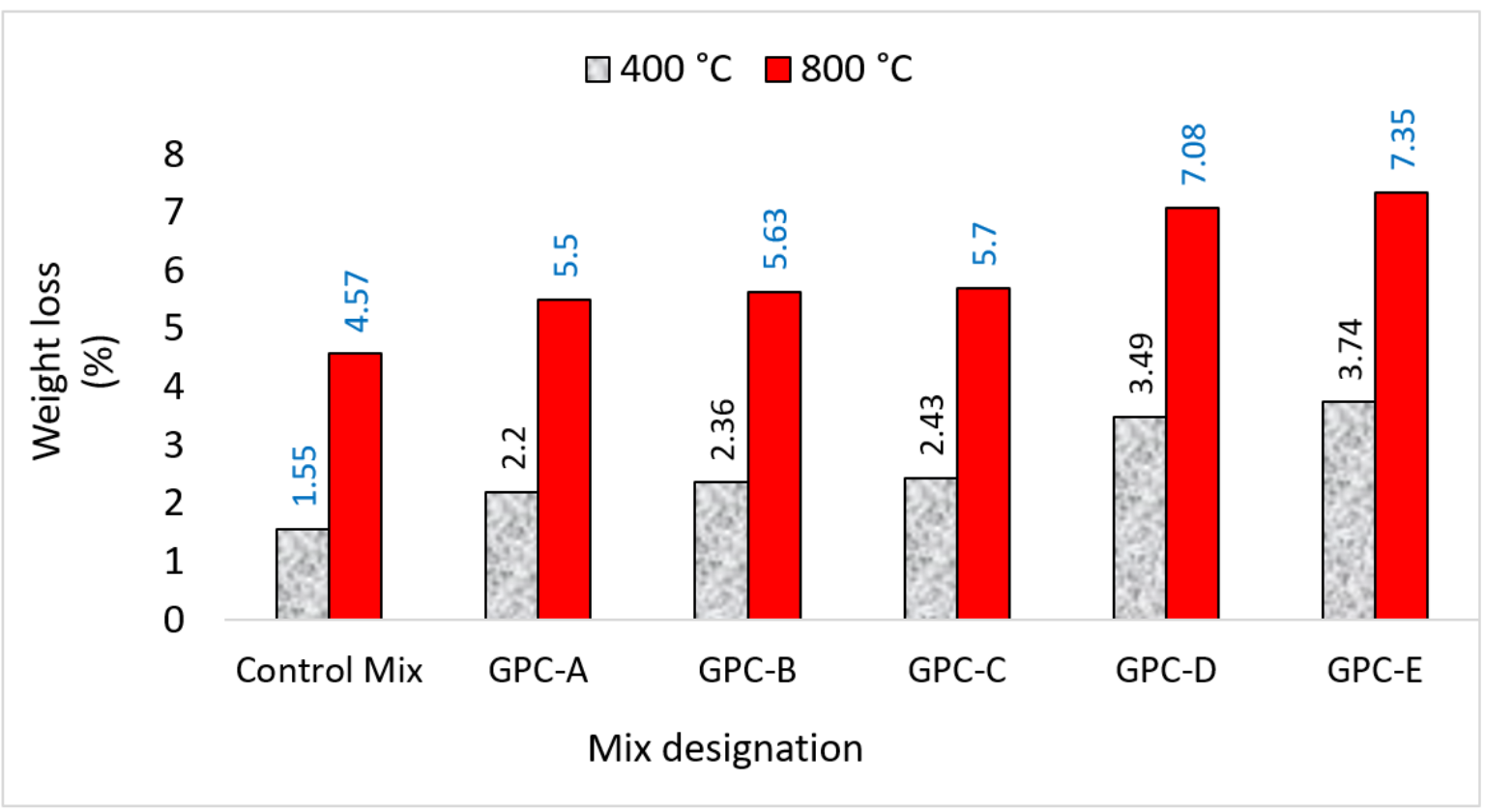

Figure 8. The weight loss in OPC and QFS-GPC specimens after exposure to $400{ }^{\circ} \mathrm{C}$ and $800{ }^{\circ} \mathrm{C}$ temperatures.

It can be concluded from the above observations that the damage extent and strength reduction appeared to be higher in those specimens with the higher calcium content. The product of $\mathrm{CaCO} 3$ decomposition resulted in the rise of volume, initiating the progress of cracks [57]. This phenomenon can be ascribed to two distinct processes occurring in the specimens as the temperature rises, i.e., the strength improvement due to the continuance of the geopolymerization process and strength loss as the thermal conflict of specimens to resist temperature elevation [53,59]. Kong et al (2010) reported that the 
thermal variability between the geopolymer matrix and aggregates is the outcome of a heavy loss of geopolymer concrete at high temperatures. The control OPC mix has maximum residual compressive strength among all the mixes. Whereas, GPC-A and GPC-E have the maximum and minimum residual compressive strengths, respectively, among all the QFS-GPC mixes. It is well established from the previous studies that the elevated temperature results in accelerating the bond-breaking process of the alkaliactivated geopolymer matrix [60-62]. In the present study, SG and QRD have higher quantities of $\mathrm{CaO}$ content, i.e., $37.33 \%$ and $47.13 \%$, respectively. It indicates that QRDincorporated GPC specimens are relatively less fire-resistant.

\subsection{X-ray Diffraction of OPC and QFS-GPC Mixes}

The XRD results are presented in Figure 9. Figure 9 illustrates the results of the XRD configuration $\left(2 \theta=10-75^{\circ}\right)$ of the control (OPC) and QFS-GPC specimens observed after the ambient curing of 28 days. The reactions in OPC and QFS-GPC mixes arise in the exceedingly significant region in a range of $2 \theta=20-30^{\circ}$. For the sample of the GPC-D mix, the sharp diversions peaks are observed in this region $\left(2 \theta=20-30^{\circ}\right)$ as compared to all other trials comprising OPC mix (control mix). These sharp peaks illustrate that the mix GPC-D is highly crystalline than other mixes of the present study. Similarly, the mixes of OPC and GPC-D in a range between $2 \theta=40-50^{\circ}$ are illustrating the peaks which represent the development of crystalline phases while the samples of other mixes (GPC-A, GPC-B, GPC-C, and GPC-E) represent the formation of amorphous phases. A previous study on the elevated temperature of geopolymer concrete showed semi-crystalline allumino silicates before and after exposure to $200^{\circ} \mathrm{C}$. The development of crystalline phases was observed in this study, which is in agreement with the previous study [58].

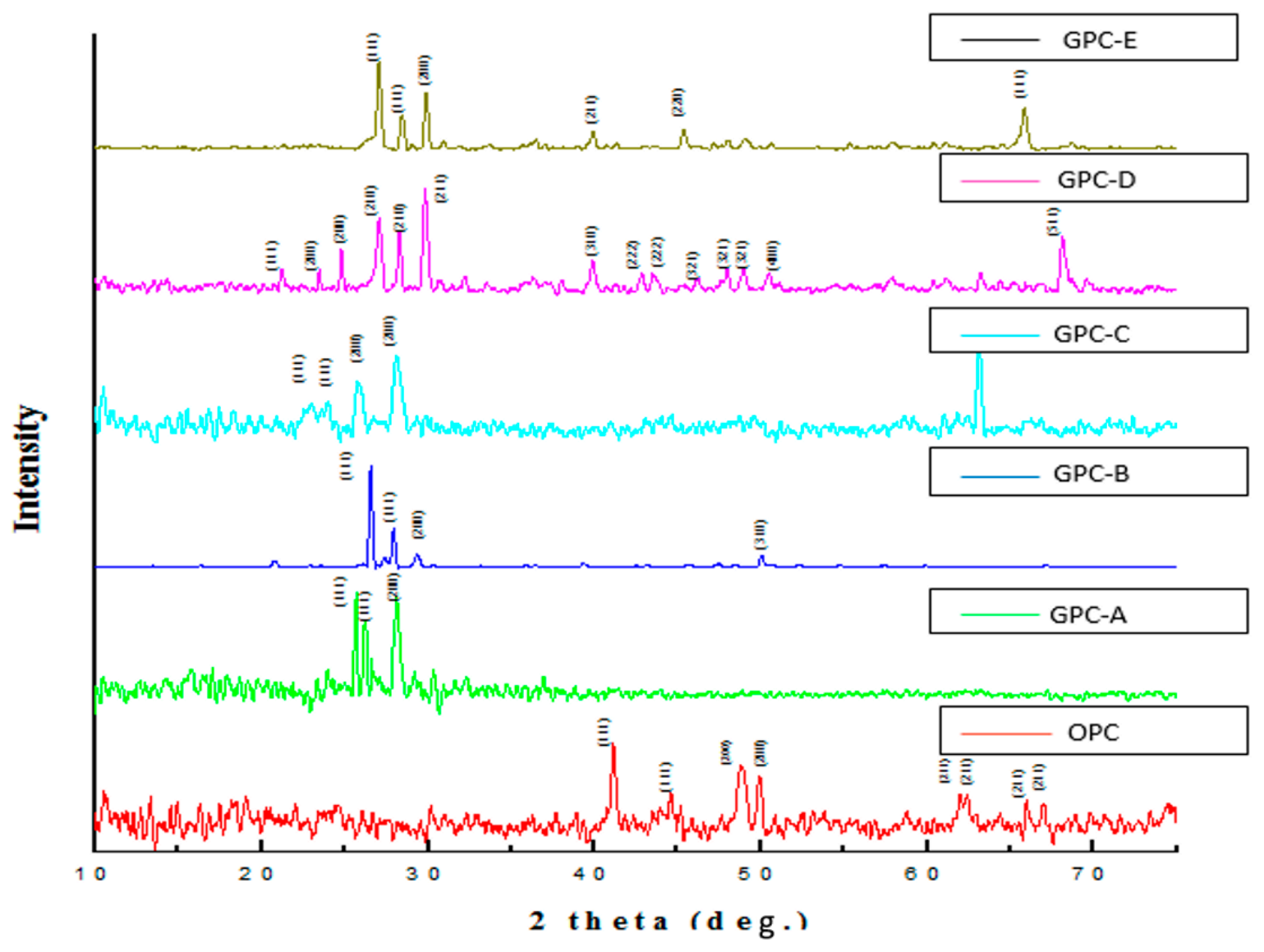

Figure 9. XRD pattern of OPC and QFS-GPC specimens. 
The restricted periodicity of particles (atoms) in the range of $2 \theta=60-70^{\circ}$ also represents in GPC-C, GPC-D, and GPC-E samples due to the presence of QRD contents. So, it can be illustrated from the XRD diffractogram that an increase of QRD contents in all QFSGPC mixes up to $15 \%$ increases the compressive strength due to the development of crystalline phases.

\section{Conclusions}

This study presented the results of an investigation to observe the influence of incorporating QRD wastes as a binding agent on the fresh and mechanical properties at ambient curing conditions of FA- and SG-blended GPC mixes, which are also exposed to elevated temperatures to observe their residual strength properties. The following conclusions can be drawn from the results of the study:

i. Increasing the QRD replacement resulted in decreasing the workability of the QFSGPC mixes.

ii. The mechanical strength of the QFS-GPC mixes generally increased by increasing the QRD content from $0 \%$ to $15 \%$, while beyond this replacement level, i.e., $20 \%$, strength decreased.

iii. GPC-D specimens prepared with 50\% FA, 35\% SG, and 15\% QRD yielded the maximum compressive strength amongst all the QFS-GPC specimens at 7, 28, and 56 days of ambient curing. The maximum splitting tensile and flexural strength was also observed in GPC-D specimens at ambient curing conditions.

iv. The residual compressive strength of the QFS-GPC mixes decreased with an increase in QRD content from $0 \%$ to $20 \%$. The weight loss after heating to elevated temperature is also consistently more in QFS-GPC specimens with increasing QRD content. It can be observed, therefore, that the QFS-GPC mixes have relatively inferior strength performance under elevated temperature as compared to OPC concrete.

v. The XRD results show that mix GPC-D has the maximum strength due to the formation of crystalline phases while in other mixes (OPC, GPC-A, GPC-B, GPC-C, and GPC-E), mostly amorphous phases were identified.

It can be inferred from this study that ternary blended GPC mixes of good quality can be produced at ambient curing conditions by incorporating the recycled QRD wastes. A compressive strength of 20-33.5 MPa can be achieved with 50\% FA and by replacing the remaining 50\% SG content with 5-20\% QRD content. The optimum content of source materials for ternary blended QFS-GPC mixes is 50\% FA, 35\% SG, and 15\% QRD, which can yield a compressive strength of $33.5 \mathrm{MPa}$, a split tensile strength of $2.12 \mathrm{MPa}$, and a flexural strength of 3.62 MPa. This optimum mix can be used for cast-in-situ applications at ambient curing conditions; however, the structural member may require fireproofing treatment.

Author Contributions: Conceptualization, K.H. and F.B.; methodology, K.H., F.B. and R.M.W.; software, K.H. and M.A.M. and E.E.H.; validation, F.B., M.I. and N.A.; formal analysis, K.H. and Z.X.; investigation, K.H. and R.F.T.; data curation, K.H.; writing-original draft preparation, K.H.; writing-review and editing, F.B, M.A. and F.A.; supervision, F.B. All authors have read and agreed to the published version of the manuscript.

Funding: This research was funded by [Taif University, Researchers Supporting Project] grant number [TURSP-2020/196].

Institutional Review Board Statement: Not applicable.

Informed Consent Statement: Not applicable.

Data Availability Statement: All the data is available within this manuscript.

Acknowledgments: Authors would like to acknowledge the finical support provided from Taif University Researchers Supporting Project Number (TURSP-2020/196).

Conflicts of Interest: The authors declare no conflict of interest. 


\section{References}

1. Mohammadhosseini, H.; Yatim, J.M.; Sam, A.R.M.; Awal, A.A. Durability performance of green concrete composites containing waste carpet fibers and palm oil fuel ash. J. Clean. Prod. 2017, 144, 448-458. [CrossRef]

2. Asaad, M.A.; Sarbini, N.N.; Sulaiman, A.; Ismail, M.; Huseien, G.F.; Majid, Z.A.; Raja, P.B. Improved corrosion resistance of mild steel against acid activation: Impact of novel Elaeis guineensis and silver nanoparticles. J. Ind. Eng. Chem. 2018, 63, 139-148. [CrossRef]

3. Fan, X.; Zhang, M. Behaviour of inorganic polymer concrete columns reinforced with basalt FRP bars under eccentric compression: An experimental study. Compos. Part B Eng. 2016, 104, 44-56. [CrossRef]

4. Reed, M.; Lokuge, W.; Karunasena, W. Fibre-reinforced geopolymer concrete with ambient curing for in situ applications. J. Mater. Sci. 2014, 49, 4297-4304. [CrossRef]

5. Deb, P.S.; Nath, P.; Sarker, P.K. The effects of ground granulated blast-furnace slag blending with fly ash and activator content on the workability and strength properties of geopolymer concrete cured at ambient temperature. Mater. Des. 2014, 62, 32-39. [CrossRef]

6. Longarini, N.; Crespi, P.G.; Zucca, M.; Giordano, N.; Silvestro, G. The advantages of fly ash use in concrete structures. Inżynieria Miner. 2014, 15, 141-145.

7. Bhattacharjee, B. Effect of relative proportion of pozzolana on compressive strength of concrete under different curing conditions. Int. J. Eng. 2008, 2, 20.

8. Vance, K.; Kumar, A.; Sant, G.; Neithalath, N. The rheological properties of ternary binders containing Portland cement, limestone, and metakaolin or fly ash. Cem. Concr. Res. 2013, 52, 196-207. [CrossRef]

9. Donatello, S.; Kuenzel, C.; Palomo, A.; Fernández-Jiménez, A. High temperature resistance of a very high volume fly ash cement paste. Cem. Concr. Compos. 2014, 45, 234-242. [CrossRef]

10. Valencia-Saavedra, W.; de Gutiérrez, R.M.; Gordillo, M. Geopolymeric concretes based on fly ash with high unburned content. Constr. Build. Mater. 2018, 165, 697-706. [CrossRef]

11. Fang, G.; Ho, W.K.; Tu, W.; Zhang, M. Workability and mechanical properties of alkali-activated fly ash-slag concrete cured at ambient temperature. Constr. Build. Mater. 2018, 172, 476-487. [CrossRef]

12. Palomo, A.; Grutzeck, M.W.; Blanco, M.T. Alkali-activated fly ashes: A cement for the future. Cem. Concr. Res. 1999, $29,1323-1329$. [CrossRef]

13. Muñiz-Villarreal, M.S.; Manzano-Ramírez, A.; Sampieri-Bulbarela, S.; Gasca-Tirado, J.R.; Reyes-Araiza, J.L.; Rubio-Ávalos, J.C.; Pérez-Bueno, J.J.; Apatiga, L.M.; Zaldivar-Cadena, A.; Amigó-Borrás, V. The effect of temperature on the geopolymerization process of a metakaolin-based geopolymer. Mater. Lett. 2011, 65, 995-998. [CrossRef]

14. Chindaprasirt, P.; Chareerat, T.; Sirivivatnanon, V. Workability and strength of coarse high calcium fly ash geopolymer. Cem. Concr. Compos. 2007, 29, 224-229. [CrossRef]

15. Somna, K.; Jaturapitakkul, C.; Kajitvichyanukul, P.; Chindaprasirt, P. NaOH-activated ground fly ash geopolymer cured at ambient temperature. Fuel 2011, 90, 2118-2124. [CrossRef]

16. Kumar, S.; Kumar, R.; Mehrotra, S.P. Influence of granulated blast furnace slag on the reaction, structure and properties of fly ash based geopolymer. J. Mater. Sci. 2010, 45, 607-615. [CrossRef]

17. Qing, Y.; Zenan, Z.; Deyu, K.; Rongshen, C. Influence of nano-SiO2 addition on properties of hardened cement paste as compared with silica fume. Constr. Build. Mater. 2007, 21, 539-545. [CrossRef]

18. Lloyd, N.; Rangan, V. Geopolymer concrete with fly ash. In Proceedings of the Second International Conference on Sustainable Construction Materials and Technologies, Ancone, Italy, 28-30 June 2010; UWM Center for By-Products Utilization: Milwaukee, WI, USA, 2010; pp. 1493-1504.

19. Rovnaník, P. Effect of curing temperature on the development of hard structure of metakaolin-based geopolymer. Constr. Build. Mater. 2010, 24, 1176-1183. [CrossRef]

20. Noushini, A.; Castel, A. The effect of heat-curing on transport properties of low-calcium fly ash-based geopolymer concrete. Constr. Build. Mater. 2016, 112, 464-477. [CrossRef]

21. Junaid, M.T.; Kayali, O.; Khennane, A.; Black, J. A mix design procedure for low calcium alkali activated fly ash-based concretes. Constr. Build. Mater. 2015, 79, 301-310. [CrossRef]

22. Rashad, A.M. A comprehensive overview about the influence of different admixtures and additives on the properties of alkali-activated fly ash. Mater. Des. 2014, 53, 1005-1025. [CrossRef]

23. Puligilla, S.; Mondal, P. Role of slag in microstructural development and hardening of fly ash-slag geopolymer. Cem. Concr. Res. 2013, 43, 70-80. [CrossRef]

24. Heniegal, A.M.A. Effect of Fine Quarry Waste on the Mechanical and Microstructures of Green Cement and Geopolymer Concrete. Elixir Int. J. 2016, 29, 42005-42014.

25. Reza, S.M.S. Experimental Studies of Strength and Cost Analysis of Mortar Using Bagasse Waste Obtained from Sugarcane Factory of Bangladesh. J. Environ. Treat. Tech. 2019, 7, 300-305.

26. Dehwah, H.A.F. Corrosion resistance of self-compacting concrete incorporating quarry dust powder, silica fume and fly ash. Constr. Build. Mater. 2012, 37, 277-282. [CrossRef]

27. Felekoğlu, B.; Tosun, K.; Baradan, B.; Altun, A.; Uyulgan, B. The effect of fly ash and limestone fillers on the viscosity and compressive strength of self-compacting repair mortars. Cem. Concr. Res. 2006, 36, 1719-1726. [CrossRef] 
28. Meisuh, B.K.; Kankam, C.K.; Buabin, T.K. Effect of quarry rock dust on the flexural strength of concrete. Case Stud. Constr. Mater. 2018, 8, 16-22. [CrossRef]

29. Ilangovana, R.; Mahendrana, N.; Nagamanib, K. Strength and durability properties of concrete containing quarry rock dust as fine aggregate. ARPN J. Eng. Appl. Sci. 2008, 3, 20-26.

30. Ortega-Zavala, D.E.; Santana-Carrillo, J.L.; Burciaga-Díaz, O.; Escalante-García, J.I. An initial study on alkali activated limestone binders. Cem. Concr. Res. 2019, 120, 267-278. [CrossRef]

31. Hake, S.L.; Damgir, R.M.; Patankar, S.V. Temperature effect on lime powder-added geopolymer concrete. Adv. Civ. Eng. 2018, 2018, 6519754. [CrossRef]

32. Saavedra, W.G.V.; de Gutiérrez, R.M. Performance of geopolymer concrete composed of fly ash after exposure to elevated temperatures. Constr. Build. Mater. 2017, 154, 229-235. [CrossRef]

33. Huseien, G.F.; Sam, A.R.M.; Mirza, J.; Tahir, M.M.; Asaad, M.A.; Ismail, M.; Shah, K.W. Waste ceramic powder incorporated alkali activated mortars exposed to elevated Temperatures: Performance evaluation. Constr. Build. Mater. 2018, 187, 307-317. [CrossRef]

34. ASTM. Standard Specification for Slag Cement for Use in Concrete and Mortars; ASTM: Conshohocken, PA, USA, 2012.

35. ASTM Committee C-09 on Concrete and Concrete Aggregates. Standard Specification for Coal Fly Ash and Raw or Calcined Natural Pozzolan for Use in Concrete; ASTM: Conshohocken, PA, USA, 2013.

36. Al-Majidi, M.H.; Lampropoulos, A.; Cundy, A.; Meikle, S. Development of geopolymer mortar under ambient temperature for in situ applications. Constr. Build. Mater. 2016, 120, 198-211. [CrossRef]

37. ASTM Committee. Standard Test Method for Sieve Analysis of Fine and Coarse Aggregates; 136-06 (2006); ASTM: Conshohocken, PA, USA, 2006.

38. ASTM Committee C43. Standard Test Method for Slump of Hydraulic-Cement Concrete; ASTM: Conshohocken, PA, USA, 2012.

39. British Standard. Testing Hardened Concrete. Making and Curing Specimens for Strength Tests; 12390-2, 2009; British Standard: London, UK, 2009; pp. 1-12.

40. ASTM Committee. Standard Test Method for Splitting Tensile Strength of Cylindrical Concrete Specimens; C496/C496M-11; ASTM: Conshohocken, PA, USA, 2011.

41. ASTM Committee. Standard Test Method for Flexural Strength of Concrete (Using Simple Beam with Third-Point Loading); ASTM: Conshohocken, PA, USA.

42. ASTM International. E119-20 Standard Test Methods for Fire Tests of Building Construction and Materials; ASTM: Conshohocken, PA, USA, 2020.

43. Kozub, B.; Bazan, P.; Mierzwiński, D.; Korniejenko, K. Fly-Ash-Based Geopolymers Reinforced by Melamine Fibers. Materials 2021, 14, 400. [CrossRef] [PubMed]

44. Temuujin, J.V.; Van Riessen, A.; Williams, R. Influence of calcium compounds on the mechanical properties of fly ash geopolymer pastes. J. Hazard. Mater. 2009, 167, 82-88. [CrossRef] [PubMed]

45. Lee, W.K.W.; Van Deventer, J.S.J. The effect of ionic contaminants on the early-age properties of alkali-activated fly ash-based cements. Cem. Concr. Res. 2002, 32, 577-584. [CrossRef]

46. Temuujin, J.; Van Riessen, A. Effect of fly ash preliminary calcination on the properties of geopolymer. J. Hazard. Mater. 2009, 164, 634-639. [CrossRef]

47. Dutta, D.; Ghosh, S. Effect of lime stone dust on geopolymerisation and geopolymeric structure. IJETAE 2012, 2, 50-57.

48. Zhang, H.Y.; Kodur, V.; Wu, B.; Cao, L.; Wang, F. Thermal behavior and mechanical properties of geopolymer mortar after exposure to elevated temperatures. Constr. Build. Mater. 2016, 109, 17-24. [CrossRef]

49. Kaosol, T. Reuse water treatment sludge for hollow concrete block manufacture. Energy Res. J. 2010, 1, 131-134. [CrossRef]

50. Ibraheem, M.; Butt, F. Fresh and Mechanical Properties of Ambient Cured Ternary Blended Geopolymer Concrete Reinforced with Steel Fibers. In Proceedings of the 2nd Conference on Sustainability in Civil Engineering, Jamshoro, Pakistan, 5-7 December 2019.

51. Mehta, P.K.; Monteiro, P.J. Concrete: Microstructure, Properties, and Materials; McGraw-Hill Publishing: New York, NY, USA, 2006.

52. Rao, K.B.; Desai, V.B.; Mohan, D.J. Experimental investigations on mode II fracture of concrete with crushed granite stone fine aggregate replacing sand. Mater. Res. 2012, 15, 41-50. [CrossRef]

53. Bakri, A.; Mustafa, A.M.; Norazian, M.N.; Mohamed, M.; Kamarudin, H.; Ruzaidi, C.M.; Liyana, J. Strength of concrete with ceramic waste and quarry dust as aggregates. Appl. Mech. Mater. 2013, 421, 390-394. [CrossRef]

54. Luhar, S.; Nicolaides, D.; Luhar, I. Fire Resistance Behaviour of Geopolymer Concrete: An Overview. Buildings 2021, 11, 82. [CrossRef]

55. Le, V.S.; Louda, P.; Tran, H.N.; Nguyen, P.D.; Bakalova, T.; Ewa Buczkowska, K.; Dufkova, I. Study on Temperature-Dependent Properties and Fire Resistance of Metakaolin-Based Geopolymer Foams. Polymers 2020, 12, 2994. [CrossRef]

56. Chithambaram, S.J.; Kumar, S.; Prasad, M. Thermo-mechanical characteristics of geopolymer mortar. Constr. Build. Mater. 2019, 213, 100-108. [CrossRef]

57. Yang, Z.; Mocadlo, R.; Zhao, M.; Sisson Jr, R.D.; Tao, M.; Liang, J. Preparation of a geopolymer from red mud slurry and class F fly ash and its behavior at elevated temperatures. Constr. Build. Mater. 2019, 221, 308-317. [CrossRef]

58. Hussin, M.; Bhutta, M.; Azreen, M.; Ramadhansyah, P.; Mirza, J. Performance of blended ash geopolymer concrete at elevated temperatures. Mater. Struct. 2015, 48, 709-720. [CrossRef]

59. Adetayo, O.A.; Dahunsi, B.I.O. Charring Rate Characteristics of Some Selected Southern Nigeria Structural Wood Species Based on Their Fire Resistance Ability. Acta Tech. Corviniensis Bull. Eng. 2018, 11, 91-96. 
60. Ismail, M.; Ismail, M.E.; Muhammad, B. Influence of elevated temperatures on physical and compressive strength properties of concrete containing palm oil fuel ash. Constr. Build. Mater. 2011, 25, 2358-2364. [CrossRef]

61. Roviello, G.; Ricciotti, L.; Ferone, C.; Colangelo, F.; Tarallo, O. Fire resistant melamine based organic-geopolymer hybrid composites. Cem. Concr. Compos. 2015, 59, 89-99. [CrossRef]

62. Waqas, R.M.; Butt, F.; Zhu, X.; Jiang, T.; Tufail, R.F. A Comprehensive Study on the Factors Affecting the Workability and Mechanical Properties of Ambient Cured Fly Ash and Slag Based Geopolymer Concrete. Appl. Sci. 2021, 11, 8722. [CrossRef] 